appointed to study particular problems. Report No. 292, for example, discusses environmental change and its impact on health, and considers such questions as the effects of ionizing radiation, air pollution, liquid and solid wastes, food hygiene and other aspects of environmental change in modern life. No. 293 discusses biological standardization, and No. 294 deals with the important question of the integration into general health services of mass cam. paigns against specific diseases. No. 295 deals with viruses and cancer, concluding that the weight of evidence suggests that at least some viruses are implicated in some forms of human cancer. Report No. 296 discusses the resistance of malaria parasites to drugs used against them. No. 297 concerns environmental health aspects of metropolitan planning and human development, and discusses such problems as the effects of overcrowding, the degradation of human environment and the pressing modern problem of noise. No. 298 deals with the organization of public dental health services, in developed and developing countries.

\section{The Agricultural Research Council of Central Africa}

The Agricultural Research Council of Central Africa is an example of a rational co-operative approach to agricultural research, combining as it does the efforts of the three territories Rhodesia, Zambia and Malawi in tackling common problems of agriculture and natural resources. The Council is jointly financed by the three territories, by Britain and by the United States, and chaired by Mr. F. C. Bawden, director of Rothamsted Experimental Station. The fifth annual report covering the year 1964 shows the breadth of interest of its developing sections, made possible by this joint approach, although the recruitment of staff did not commence until 1962 (Pp. 64, Salisbury, Rhodesia: Agricultural Research Council of Central Africa, 1965). The Council's research projects span the fields of soil productivity, animal productivity, grain-legume pathology, forest genetics, tsetse-fly problems, hydrology and biometry. These research projects reflect in choice and in emphasis the particular problems of these territories as, for example, the intense activity of the large team engaged in tsetse-fly research in which the U.S. Department of Agriculture is actively co-operating. As might be expected in such a young organization, the staffing and development of the sections varies a great deal; so also does the approach to problems varying, for example, from a basic study of haemoglobin polymorphism in cattle, carried out by the Nutrition and Biochemistry Section, to the more applied studies on the effect of sulphur on crop yields in the area, carried out by the Soil Chemistry section.

\section{National Parks of Queensland}

THe Premier's Department of the State Public Relations Bureau, Brisbane, has published an illustrated booklet describing the amenities of the national parks of Queensland, which are under the control of the State Forestry Department. As a matter of government policy upheld by legislation, they are reserved in perpetuity as areas of scenic, scientific, historic and recreational interest. Untouched and unspoilt in all essential respects, they are administered as a natural haven and habitat for native animals and birds, so that the distinctive flora and fauna can live unmolested by man. Aboriginal relics, including cliff paintings, drawings and burial caves, are also preserved. Provision was first made for the reservation of national parks in Queensland with the passing of the State Forest and National Parks Act of 1906. The first national park in Queensland, covering an area of 324 acres at Witches Falls, Tamborine Mountain, was proclaimed in the year 1908. At the present time the area so reserved totals 975,548 acres. It is the ultimate goal of the Department of Forestry to have represented, within these reservations, all the many types of bushland which occur in Quoensland.

\section{Studies in Speleology}

Studies in Speleology, a new journal devoted to caves, has recently been launohed. It came into being as an unexpected by-product of the purchase of a disused limestone quarry at Buckfastleigh in Devon, containing the entrances of five caves of considerable scientific interest, by the Society for the Promotion of Nature Reserves, in November 1961. In March 1962 it was decided that the property should be developed as a teaching and research centre, to be named the William Pengelly Cave Research and Demonstration Centre. Already a palaeontological demonstration has been prepared in Joint Mitnor Cave, work has begun on the conversion of two old buildings into a cave-museum, lecture hall and other accommodation, and the first volunteer guide-naturalists have been trained to explain the various features of the Centre to visiting cavers, students and naturalists. The Centre will not be open to the general public. In December 1962 the Association of the Pengelly Cave Research Centre, whose headquarters are in London, was founded with the object of establishing an international membership to help support the Centre. Members drawn from as far afield as the United States, Canada, Australia, New Zealand, South Africa, Angola, Kenya, Rhodesia, Singapore, Spain, France, Holland and Poland already number nearly 300. Studies in Speleology is the journal of this Association. Linked to a London lecturo programme, it forms an extension of the planned activities of the Centre. Hitherto, there has been in Britain no journal the prime object of which is to encourage cave conservation by providing a link between those concerned with the exploration of caves on one hand, and scientific speleology on the other. Careful exploration can lead to scientific interest as underground problems become apparent; careless exploration can easily lead to the destruction of the evidence before the problems have been realized. Copies of the journal are available, price 25s., or 3.75 dollars, from Mr. M. A. Rennie, 40 Bradley Gardens, Ealing, London, W.13, or E. Taylor, 142 Lloyd Avenue, Pittsburgh 18, Pennsylvania.

\section{Electronics Letters}

To facilitate the rapid communication of new information and the interchange of ideas in the electronies field is the declared aim of a new international research journal published by the Institution of Electrical Engineers. The first issue of the journal, entitled Electronics Letters, appeared in March, and it will be published monthly (1, No. 1. Pp. 1-28. London: The Institution of Electrical Engineers, 1965. Annual subscription, 50s.; single issues, $5 s$.). Communications to the journal recording research results or observations on important topics of current interest take the form of letters some 1,200 words long and comprising not more than two illustrations. A letter accepted for publication will normally appear within 2-6 weeks of being recoived. While the preferred language is English, letters will be accepted for publication in Russian, French, German or Italian, but must be accompanied by a title and synopsis in English. The editorial board is international. The field of interest is stated to be electronic science and engineering, radio and automatic control. The first issue contains twenty-six letters, most of which deal with exporimental research, novel techniques and devices, but several treat wholly theoretical topics. Only one lotter is in a language other than English. The amount of space allocated to each letter appears to be sufficient to provide for concise exposition, the presentation of essential results and necessary graphical illustration. The urgent noed for rapid publication is evident, and this new journal appears both in design and execution to be well fitted to this purpose. It will be warmly welcomed not only by those engaged in radio and electronic research, but also by many who utilize electronic techniques in other branches of science. 